yuccal and pyrophocal. An examination of the contents of each extract showed a different quantita ve Saponin was found in all parts of the plant:

Many of the above facts have been collected from the ments, selected from a nass of material, as evidences in favor of the view stated at the beginning of this
paper. ${ }^{~}$ My own study has been directed toward the discovery of saponin in those plants where it was presumably to be found. The practical use of this theory in plant analysis will lead the chemists at once to a are probably present.

I have discovered saponin in all parts of the Yucca angustifolia, in the Y. filimentosa and $Y$. gloriosa, in several species of agavæ, and in plants belonging to The list ${ }^{2}$ of plants in which saponin has been discovered is given in the note. All these plants are conplants containing saponin have been found among apetalous groups. No plants have been found containing The plane of saponin passes from the liliacex and allied groups to the rosales and higher dicotyledons. Saponin belongs to a class of substances called gluco-
sides. Under the action of dilute acids, it is split up into two substances, glucose and sopogenin. The chemical nature of this substance is not thoroughly un mixture of several substances. This complexity of chemical composition of saponin is admirably adapted for the nutrition of the plant, of the morphological elements of the plant's organs. of the morphological elements of the plant's organs. plant to direct the distribution of its carbon, hydrogen, The solvent action of saponin on resins has been al
its higher functions and The solvent action of saponin on resins has been al-
ready discussed. Saponin likewise acts as a solvent ready discussed. Saponin likewise acts as a solvent solvent of insoluble or slightly soluble salts would assist the plant in obtaining food, otherwise difficult of Saponin is found in endogens and exogens. The line dividing these two groups is not always clearly defined. Statements pointing to this are fonnd in the

Smilax belongs to a transition class, partaking some-
what of the nature of endoren and of worthy of note that sarsaparillas should contain saponin. It is a significant fact that all the groups above
named containing saponin belong to Heckel's middle division.

ive saponin is thus a constructive element in developing the plant from the multipliIt has been observed that the composite occurs where the materials for growth are supplied in greatest sources of nutrition are remote. We may gather from
this fact that the simpler organs of plants low in the evolutionary scale contain simpler non-nitrogenous
chemical compounds for their nutrition. The presence of saponin seems essential to the life of principle in the progression of certain lines of plants, passing from their lower to their higher stages. Saponin is invariably absent where the floral elements
are simple; it is invariably absent where the floral lements are condensed to their greatest position is plainly that of a factor in the great middle vidual are striving to condense, and thus increase their

physiological action and the economy of parts.
It may be suggested as a line of research to study what are the conditions which control the synthesis and gradual formation of saponin in plants. The simpler compounds of which this complex substance is built up, if located as compounds of lower plants,
would indicate the lines of progression from the lower to the saponin groups. the American Association for the Advancement of Sci compounds should be used as a means of botanical classificatio

The botanical classifications based upon morphology are so frequently unsatisfactory, that efforts in some directions have been made to introduce other methods.
There has been comparatively little study of the chemical principles of plants from a purely botanical The leguminosæ are conspicuous as furnishing us with important dyes, $e$. g., indigo, logwood, catechin. species of the genus Indigofera, and logwood from the Homatoxylon and Saraca indica.
The discovery of hæmatoxylin in the Saraca indica The discovery ${ }^{9}$ of hæmatoxylin in the Saraca indica
illustrates very well how this plant in its chemical, as well as botanical, character is related to the Homatoxy catechin in the Saraca. This compound is found in the acacias, to which class Saraca is related by its chemical position, as well as botanically. Saponin is found in both of these plants, as well as in many other plantso the leguminosæ. The leguminosæ come under the mid-
dle plane or multiplicity of floral elements, and the presence of saponin in these plants was to be expected. From many of the facts above stated, it may be in

1 For further facts confrming this theary, see "Comparative Chemistry
of Higher and Lower Plants." By H. C. De S. Abbott. Amer. Nattural.
ist, Augnat, 1887.

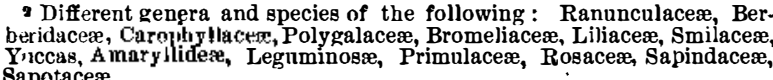

Sapotacex.
3 Kobert: Chem. Ztg.

4 Compt. Rend., xciv, p. 1124.

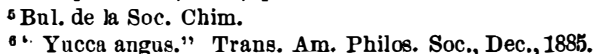

"Botanical Gazette, October, 1886.

Nat.. xiii.
H. Ce S. Abbott, Proc. Acad. Nat. Sciences, Nov. 30, 1886. occur at random. Each stage of yrowth and develop-
ment has its own particular chemistry. It is said that many of the constituents found in
It are of no further use in the plant'seconomy. This subject is by no means settled, and even should we be orced to accept that ground, it is a significant fact secrete or excrete chemical compounds peculiar to
them, which are to be found in one family, or in speIt is a fact that to it.

It is a fact that the chemical compounds are there, ur purposes of study and classification.

The result of experiment shows that the presence pment of all plants and particular compounds to the development of certain plants. Plant chemistry and orphology are related. Future investigations will In general terms, we may say that amides and carbo-
hydrates are utilized in the manufacture of proteids Organic acids cause a turgescence of cells. Glicosides may be a form of reserve food material.

Resins and waxes may serve only as protection to the surfaces of plants ; coloring matters, as screens to shut off or admit certain of the sun's rays; but we are still
far from penetrating the mystery of life. A simple plant does what animals more highly enawed cannot do. From simplest substances they
manufacture the most complex. We owe our existence manufacture the most complex. We owe our

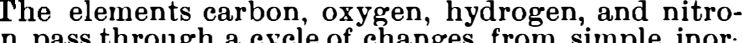
anic substances to the complex compounds of the living cell. Upon the decomposition of these bodies the elements return to their original state. During ere mentioned at the beginning, in turn, follow
their path. From germination to death this course ppears like a crescent, the other half of the circle is difficult to say.-Jour. Fr. Inst.
inger.

NEW METHOD FOR THE QUANTITATIVE DETERMINATION OF STARCH.

$$
\text { A. V. AsBoth. }
$$

THE author maintains that unsatisfactory results ar employed is based upon the inversion of sugar, formed evulose are partly decomposed by boiling with dilute

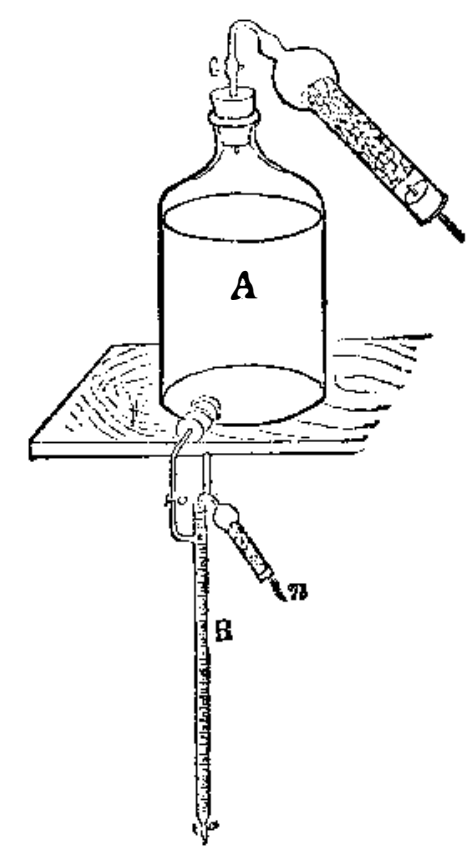

cids. He proposes to replace the methods hitherto a barium salt of starch, to which he assigns the formula BaO. ${ }_{24} \mathrm{H}_{40} \mathrm{O}_{20}$. This salt is sparingly soluble in water and insoluble in dilute alcohol.

In making a determination a weighed quantity of
tarch is sacharified with water, then mixed with xcess of normal baryta solution, dilute alcohol adde to make up to a certain volume, and, after the precipiwith acid.

The author also describes the apparatus he employs atter is contained in the bottle, $A$, and the drying tube latter is contained in the bottle, $A$, and the drying tube
attached to the neck of the same is filled with quick-
lime. The burete, B, which is in direct connection lime. The burette, B, which is in direct connection
with the bottle, may be filled with the solution by opening the stop cock, and the small drying tube, $n$, is
filled with dry KOH, thus preventing the entrance of any $\mathrm{CO}_{2}$. Numbers are appended which seem to author finally gives a detailed account of the entire analysis of various cereals. $-A$. R. in Jour. Soc. Chem.
and

\section{SYNTHESIS OF THE ALKALOIDS.}

In the note on the constitution of alkaloids in a recent issue, we referred more especially to what we may
term the less highly organized bases. Most of our knowledge, as we now have it, regarding such alkaloids as muscarine and choline has been aequired during the past dozen years. This is not exactly the case
with the higher groups of alkaloids-the derivatives of pyridine and quinoline. It so happens that the oldest alkaloids are in these groups. They have, almost
necessarily, been subjected to a longer period of attack, necessarily, been subjected to a longer period of attack,
but the extreme complexity of their molecules, and the infinite number of differing parts or substances into main cause of the small progress which has been made main cause of the small progress which has been made
in this department. All, however, yield one or more
bodies or bases in common, while each has its distinctive and peculiar decomposition product. For exam- ple, cinchonine and quinirie both afford the basic quinoline under certain conditions, but on oxidation is the principal body formed, while in the case of quiThe acquirement through experiment of such knowledge as that is, however, so much gained. We find indeed, that obstacles are gradually being cleared loids as piperidine and coniine is a proof that the chemist is on the right track in studying the decompo-
sition products, and building up from them, theoretically, bodies of similar constitution. It is noteworthy the most brilliant discoveries of the present day, especially in the discovery of dye stuffs. Many of our quinine substitutes, such as thalline, for example, are If there is romance in chemistry at all, it is to be found certainly in this branch of it, which is generally con-
sidered the most uninteresting and unfathomable. We may take piperidine and coniine as examples of the methods followed in alkaloidal synthesis; these are
pyridine bases. Pyridine has the formula $\mathrm{C}_{5} \mathrm{H}_{5} \mathrm{~N}$, that is, it is benzene with $\mathrm{CH}$ replaced by $\mathrm{N}$. The relationing formulæ :

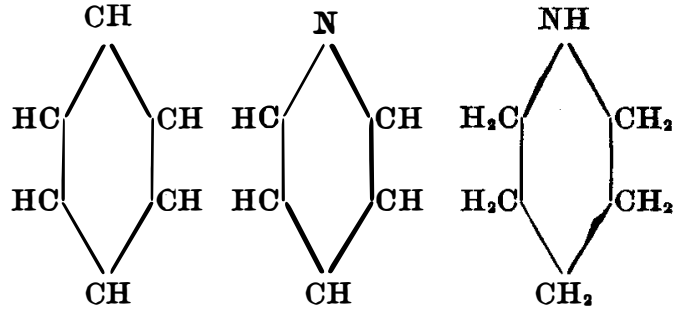

(Benzene, $\mathrm{C}_{6} \mathrm{H}_{6}$.) (Pyridine, $\mathrm{C}_{6} \mathrm{H}_{6} \mathrm{~N}$.) (Piperidine, $\mathrm{C}_{6} \mathrm{H}_{11} \mathrm{~N}$.)

If we introduce six hydrogen atoms into pyridine, we
convert it into piperidine. Ladenburg succeeded in so hydrogenizing pyridine by acting upon an alcoholic solution with sodium, and from the base which was
formed he obtained a platinochloride which agreed with the similar double salt of piperidine. He has also prepared it from trimethyline cyanide by the action of
sodium. Pentamethylinediamine is the principal intermediary product, and this gives piperidine when the alkaloid so obtained is identical with that prepared the alkaloid so obtained is identical with that prepared
from piperine. Another curious point which Ladenburg has lately proved is that cadaverine (one of the
products of flesh decomposition) is identical with pentamethylinediamine, and that its imine is the same as
piperidine. The synthesis of coniine by Ladenburg is one of the most notable achievements of modern chemistry. He at first supposed that this alkaloid was by the isopropyl radical $\left(\mathrm{C}_{3} \mathrm{H}_{7}\right)$, its formula being taken as $\mathrm{C}_{5} \mathrm{H}_{9}\left(\mathrm{C}_{8} \mathrm{H}_{7}\right) \mathrm{NH}$. But he has since changed his view,
as will be seen from what follows. In its synthesis as will be seen from what follows. In its synthesis
1,000 grammes of picoline were first converted into alphapicoline, 380 grammes being obtained. This was heated with paraldehyde, whereby it was converted
into allyl pyridine (48 grammes), and this by reduction with sodium yielded alpha-propylpyridine, a body in important difference was its optical inactivity, but he succeeded in splitting up a solution of the acid tartrate
of the base by means of Penicillium glaucum. Crystals separated which had a dextro-rotatory power of
$[a]_{\mathrm{D}}=31^{\circ} 87^{\prime}$ as compared with the $[a]_{\mathrm{D}}=13^{\circ} \quad 79^{\prime}$ of $[a]_{\mathrm{D}}=31^{\circ} 87^{\prime}$ as compared with the $[a]_{\mathrm{D}}=13^{\circ} 79^{\prime}$ of
natural conine. This brief account conveys but a faint idea of the difficulties which were encountered in
these researches. Optical methods of examination have proved of great value, and are destined to play an important part in such work. quinine group. As yet chemists have got no further with these than the oxidation products; but the study
has afforded us several new antipyretics and many has afforded us several new antipyretics and many
interesting facts. It has been found, for example, that artificial quinine-like bodies, which fluoresce and give have antipyretic properties like quinine, but their use. If effects are so pernicious as to prevent their use. If, however, such bodies are hydrogenized or
methylated they lose their fluorescing property, do not give the green color, and their secondary effects
are removed. Knowledge of these facts led to the discovery of thalline. It is prepared from paraquinanisol, one of the objectionable bodies, by reduction with tin the constitutional relationship of these compounds :

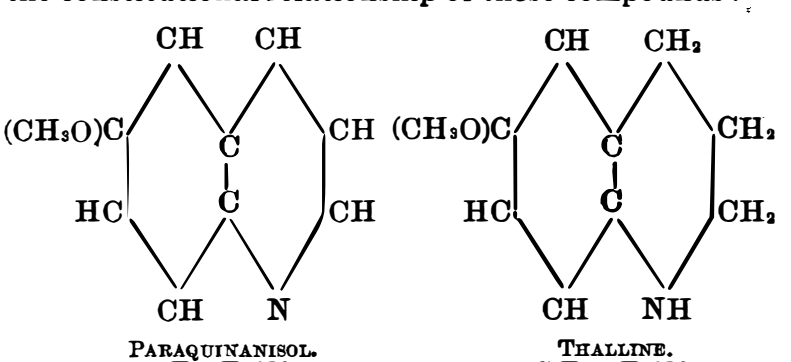

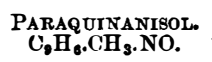

$\underset{\mathrm{C}_{9} \mathrm{H}_{20} \cdot \mathrm{CH}_{3} . \mathrm{NO} \text {. }}{\text { THaLine. }}$

It is evident from the difficulties which have been encountered in this department of chemistry, and more will be many years before it will influence the manufacture of alkaloids from the drugs which yield them. Ladenburg has synthetized coniine, but he has not yet
ventured to assert that his produet will replace the ventured to assert that his produet will
natural alkaloid.-Chem. and lnruggist.

THE Southern California Advocate reports another Sagnificent donation of lands to the University of
Southern California by Mr. D. Freeman, the owner of the Centinella ranch near Los Angeles-six hundred thousand dollars in all given to found a school of ap$\$ 500,000$ for endowment. The buildings will be in the
plied sciences $\$ 500,000$ for endowment. The buildings will be in the
vicinity of Inglewood, the new and beautiful town on
the Ballona branch of the California Central. 